\title{
La cartografía colonial española durante la Segunda República (1931-1936) ${ }^{1}$
}

\section{Spanish colonial cartography during the Second Republic (1931-1936)}

\author{
Luis Urteaga y Francesc Nadal*
}

La Segunda República heredó un modesto y fragmentado imperio colonial en África, compuesto por tres territorios de muy desigual extensión e importancia: el Protectorado de España en Marruecos, el territorio del Sahara y las colonias del Golfo de Guinea. A estas dispersas posesiones se añadió durante la etapa republicana el pequeño enclave de Sidi Ifni (Ait-Bu-Amaran), ocupado por el ejército español en abril de 1934. En conjunto, las posesiones españolas sumaban alrededor de 350.000 kilómetros cuadrados, con una población total ligeramente superior al millón de habitantes.

El conocimiento geográfico de estos territorios era deficiente. No existían mapas a gran escala completos de ninguna de las colonias, y tampoco había podido efectuarse la demarcación de sus fronteras. La cartografía de los territorios del Golfo de Guinea era exigua, y la del Sahara, si cabe, aún más escasa e imprecisa. La prioridad de la cartografía colonial, y la práctica totalidad de

\footnotetext{
${ }^{1}$ Este trabajo se ha realizado en el marco del proyecto de investigación 2007 EBRE 2, financiado por la Agència de Gestió d'Ajuts Universitaris i de Recerca de la Generalitat de Catalunya. Queremos agradecer a Pilar Casado Liso, directora del archivo histórico del Ministerio de Asuntos Exteriores y de Cooperación (Madrid), y a Luis Magallanes Pernas, director técnico del archivo cartográfico del Centro Geográfico del Ejército (Madrid), las orientaciones recibidas para localizar los fondos cartográficos y documentales utilizados en esta investigación.

* Luis Urteaga. Universitat de Barcelona (urteaga@ub.edu), Francesc Nadal. Universitat de Barcelona(fnadal@ub.edu).
} 
los recursos disponibles, se habían asignado al Protectorado español de Marruecos, donde una unidad dependiente del Depósito de la Guerra, la Comisión Geográfica de Marruecos, venía trabajando con continuidad desde 1882.

La administración republicana se encontró así con unas necesidades cartográficas agudizadas, y con un modelo de trabajo y unas prioridades establecidas desde hacía décadas. ¿Llegó a modificar este esquema? ¿Cuál fue su política cartográfica? ¿Cuáles fueron las principales realizaciones del período?

La respuesta a estas preguntas es, hasta el momento, confusa y bastante contradictoria. La historiografía militar franquista ha sido muy dura al juzgar la experiencia republicana, dejando una imagen profundamente negativa del trabajo realizado (Alonso Baquer, 1972), o negando, simplemente, que se hubiese realizado trabajo alguno (González de Mendoza, 1972). Desde esta perspectiva se ha enjuiciado la política cartográfica de la República como un intento deliberado de socavar la capacidad cartográfica del Ejército, y de destruir las instituciones especializadas en cartografía militar y colonial2. Tales juicios, sin embargo, se apoyan en una base empírica muy endeble, y están ayunos de contraste documental. Los fondos cartográficos de la etapa republicana custodiados en el Centro Geográfico del Ejército están sólo parcialmente catalogados. Las primeras catas que hemos podido realizar en el estudio de esa documentación ofrecen un resultado muy distinto al sugerido hasta ahora (Nadal, Urteaga y Muro, 2000). En realidad, como se tratará de demostrar, la cartografía colonial brinda un rotundo desmentido a la visión de los años de la República como una etapa de parálisis, o aún de ruptura con la experiencia anterior.

El objetivo de este artículo es sustituir el juicio por el dato, el invento por la evidencia. Está dividido en cinco partes. La primera ofrece una breve descripción del marco institucional de la cartografía colonial, e identifica a sus artífices. La trayectoria posterior de la mayor parte de ellos, en la guerra civil española y en la larguísima posguerra, queda convenientemente iluminada a la luz de su experiencia africana. Las partes segunda y tercera dan cuenta los trabajos cartográficos realizados en el Protectorado español de Marruecos desde 1931 a 1936. La cuarta da noticia del levantamiento del mapa topográfico de

\footnotetext{
2 Son significativas, en este sentido, las duras palabras del teniente general Ángel González de Mendoza Dorvier, escritas en 1972, cuando era Presidente del Consejo Superior Geográfico: «Al advenimiento de la República de 1931 se quiso suprimir a las Fuerzas Armadas no sólo la colaboración en la formación de la cartografía militar, sino toda actividad cartográfica organizada» (González de Mendoza, 1972, viI). En 1931 Ángel González de Mendoza era capitán de Estado Mayor y estaba destinado en la Sección Cartográfica del Estado Mayor Central.
} 
Sidi Ifni, iniciado en 1934 nada más realizarse la ocupación del territorio. La quinta, por último, analiza el proceso de reorganización de la cartografía colonial llevado a término en la etapa postrera del régimen republicano.

\section{La Comisión Geográfica de Marruecos y Límites}

Desde el siglo XIX, la responsabilidad sobre la cartografía colonial estaba encomendada al Cuerpo de Estado Mayor del Ejército, y se ordenaba mediante un servicio especializado que recibía el nombre de Depósito de la Guerra. El Depósito de la Guerra creó en 1882 una unidad cartográfica específica con la misión de efectuar levantamientos en territorio marroquí, que inicialmente recibió el nombre de Comisión de Estado Mayor en Marruecos. Posteriormente la misma unidad pasó a denominarse Comisión Topográfica de Marruecos (1910-1920), Comisión Geográfica de Marruecos (19201925) y Comisión Geográfica de Marruecos y Límites (1925-1935). Los sucesivos cambios de nombre no significaron, sin embargo, mudanza de propósito.

La llegada de Manuel Azaña al Ministerio de la Guerra, el 14 de abril de 1931, dio lugar a una reorganización importante de los servicios cartográficos militares. El Depósito de la Guerra cambió su nombre por el de Sección Cartográfica del Estado Mayor Central, y algunas de sus competencias en materia de cartografía topográfica fueron transferidas a un organismo civil: el Instituto Geográfico y Catastral ${ }^{3}$. Los cambios funcionales y organizativos, sin embargo, quedaron modulados por claros elementos de continuidad. Uno de ellos resultará revelador: el coronel de Estado Mayor Manuel Lon Laga (18771936), que había sido nombrado jefe del Depósito de la Guerra en 1928, durante la Dictadura de Primo de Rivera, siguió como jefe de la Sección Cartográfica del Estado Mayor Central hasta 1933, año en que se produjo su ascenso a general de Brigada. Le sucedió en el mando el coronel Antonio Aranda Mata (1888-1979), que había ostentado la jefatura de la Comisión de Marruecos desde 1923 hasta 1930. En cualquier caso, los cambios introducidos por Manuel Azaña no afectaron para nada a la labor desarrollada en África ${ }^{4}$.

\footnotetext{
3 Decreto de 28 de julio de 1931 sobre reorganización de los servicios cartográficos.

${ }^{4}$ Así se señala explícitamente en el artículo $3^{\circ}$ del decreto citado de 28 de julio de 1931: La Comisión Geográfica de Marruecos continuará «como en la actualidad y con los mismos cometidos que hoy tiene».
} 
La Comisión de Marruecos era la mayor de las unidades dependientes de la Sección Cartográfica del Estado Mayor Central, y la única especializada en cartografía colonial. Tal como se ha indicado, había sido creada en 1882, y desde entonces venía trabajando ininterrumpidamente sobre territorio marroquí, manteniendo una notable producción cartográfica (Urteaga, 2006a y 2006b; Urteaga, Nadal y Muro, 2003 y 2004). Desde el establecimiento del Protectorado de España en Marruecos, en 1912, la Comisión tenía a su cargo la formación de la cartografía topográfica del Protectorado, y desde 1926 también la demarcación de la frontera con el Protectorado de Francia, de ahí su nombre oficial de «Comisión Geográfica de Marruecos y Límites».

En 1931 la unidad estaba bajo el mando del teniente coronel Federico Montaner Canet (1874-1938), un veterano jefe del Cuerpo de Estado Mayor que había dedicado prácticamente toda su carrera a tareas cartográficas 5 . Ingresado en el Cuerpo de Estado Mayor en 1903, Montaner Canet había tomado parte en el levantamiento de la frontera hispano-francesa desde 1904 a 1914. Posteriormente, se hizo cargo de la jefatura de la Comisión Geográfica de los Pirineos, demostrando energía y capacidad organizativa. En 1927 fue destinado al Protectorado como segundo jefe de la Comisión Geográfica de Marruecos y Límites. Pasó a desempeñar la jefatura de esta unidad en 1930, tras el pase a la Península de su anterior responsable, el coronel Antonio Aranda Mata.

Montaner Canet tenía a sus órdenes un cohesionado equipo de cartógrafos integrado por cuatro comandantes de Estado Mayor, cuatro capitanes del mismo cuerpo, y un comandante de Infantería que estaba agregado a la sección de Límites. El hombre con más experiencia en asuntos marroquíes de entre todos ellos, era el comandante de Infantería Jesús Jiménez Ortoneda (18871976). Había llegado a Melilla en 1907, siendo un joven teniente de Infantería, y no se había movido de África desde entonces. Destinado a las tropas de Policía Indígena, aprendió árabe y amazigh, y alcanzó el cargo de interventor militar y jefe del servicio de información de la Oficina Central de Intervenciones de Melilla. Dado su excelente conocimiento de la región oriental del Rif, y su familiaridad con las cabilas de la zona fronteriza, en 1926 quedó agregado a la sección de Límites de la Comisión Geográfica de Marruecos ${ }^{6}$. Entre los oficiales y jefes del Cuerpo de Estado Mayor, el más veterano en Marruecos era el comandante Félix Pérez Gluck, que había sido destinado a la Comisión de

\footnotetext{
${ }^{5}$ Archivo General Militar de Segovia. En adelante se citará AGMS. Leg. M-3.786.

${ }_{6}^{6}$ AGMS, Leg. J-53. Sobre la personalidad de Jiménez Ortoneda y su trayectoria profesional puede verse Villanova y Urteaga, 2009.
} 
Marruecos en 1919, y no había cambiado de destino desde entonces. El resto llegaron a Marruecos prácticamente a la par que su jefe (ver cuadro 1).

\section{CUADro 1}

ORGANIZACIÓN, PERSONAL DE LA COMISIÓN GEOGRÁFICA DE MARRUECOS Y LÍMITES, Y PERÍODO DE PERMANENCIA EN LA UNIDAD

\begin{tabular}{lll}
\hline Jefatura & $\begin{array}{l}\text { Teniente coronel Federico Montaner Canet } \\
\text { Teniente coronel Aresio Viveros Gallego }\end{array}$ & $\begin{array}{l}1927-1934 \\
1934-1936\end{array}$ \\
\hline Sección Geográfica & Comandante Félix Pérez Gluck & $1919-1936$ \\
& Comandante José Millán Díaz & $1927-1936$ \\
& Comandante Manuel Lombardero Vicente & $1927-1936$ \\
& Capitán Aurelio Matilla Jimeno & $1927-1936$ \\
& Capitán Antonio Gómez Goya & $1928-1936$ \\
& Capitán José Ruiz-Fornells Ruiz & $1931-1936$ \\
\hline Sección de Límites & Comandante Darío Gazapo Valdés & $1927-1936$ \\
& Capitán Carmelo Medrano Ezquerra & $1931-1936$ \\
& Comandante Jesús Jiménez Ortoneda & $1926-1932$
\end{tabular}

Fuente: Elaboración propia a partir de Anuario Militar de España, 1931-1936 y expedientes personales del AGMS

El trabajo de campo en el Protectorado requería una buena dosis de experiencia y conocimiento del medio. En este sentido, la estabilidad del personal constituía un factor positivo, y seguramente resultaría imposible encontrar en todo el Ejército de África una unidad más estable que la Comisión Geográfica de Marruecos. Las autoridades republicanas no tocaron para nada la composición ni las competencias de la unidad, hasta la reorganización de los servicios de cartografía colonial operada en 1935, que será tratada más adelante. El único cambio digno de mención ocurrió en 1934, cuando debido al ascenso a coronel de Federico Montaner Canet, este fue substituido en la jefatura por el teniente coronel de Estado Mayor Aresio Viveros Gallego ${ }^{7}$.

7 Aresio Viveros Gallego (1881-1970) inició su carrera como Ingeniero militar, alcanzando el empleo de capitán de Estado Mayor en 1913. Tras un período destinado en el Depósito de la Guerra, en 1919 se incorporó como profesor topografía y matemáticas a la Escuela Superior de Guerra, desempeñando esta actividad durante más de doce años en dos etapas distintas: de 1919 a 1926 y de 1930 a 1934. Desde 1926 a 1928 estuvo en Marruecos como jefe de la sección de servicios de la Comandancia General de Melilla, y tomó parte en la fase final de la guerra del Rif (AGMS, Sección CG2, Caja 188/12). 
Los jefes y oficiales de la Comisión Geográfica eran la cabeza de una robusta organización cartográfica, que no tenía parangón en la Península. Estaba integrada por casi un centenar de especialistas pertenecientes a la Brigada Obrera y Topográfica de Estado Mayor, entre los que figuraban dos jefes de taller, tres subjefes, 28 maestros de taller y 60 obreros topógrafos ${ }^{8}$. A este equipo deben agregarse los portamiras nativos y el personal auxiliar encargado del transporte de víveres e impedimenta. En su conjunto, la salida al campo de las partidas de trabajo suponía la movilización de más de 200 personas simultáneamente. ¿A qué se dedicaba este nutrido contingente?

\section{LA ACTIVIDAd CARTOGRÁFICA EN EL PROTECTORADO: \\ LAS TAREAS DE LA SECCIÓN GEOGRÁFICA}

La Comisión de Marruecos estaba funcionalmente dividida en dos secciones: la Geográfica, con sede en Ceuta, que era la encargada de los levantamientos topográficos regulares, y la de Límites, con sede en Melilla, que tenía a su cargo el deslinde de la frontera hispano-francesa en Marruecos. La principal de las misiones encomendadas a la sección Geográfica era el levantamiento del Mapa topográfico del Protectorado de Marruecos a escala 1:50.0009.

La formación de este mapa había sido ordenada por el Depósito de la Guerra en 1927, una vez concluida la guerra del Rif. A partir de la citada fecha, el mapa del Protectorado constituyó la principal prioridad de la cartografía militar española. La coyuntura colonial explica parcialmente esta prioridad. La carta topográfica constituía un paso obligado para abrir una nueva fase en la implantación colonial en el norte de África, así como para asegurar el control militar del territorio (Villanova, 2004). La necesidad de reforzar el control estratégico del hinterland continental de las Islas Canarias, en la época inicial del desarrollo de la navegación aérea, aportó un estímulo adicional a la empresa cartográfica marroquí.

El mapa del Protectorado de Marruecos, que recibió la denominación oficial de Mapa provisional en escala 1:50.000, consta de 20 hojas, cada una de

\footnotetext{
${ }^{8}$ Diario Oficial del Ministerio de la Guerra, no 126, 1929.

9 Hemos estudiado con bastante detalle la génesis y el levantamiento de este mapa en un trabajo anterior: Nadal, Francesc; Urteaga, Luis y Muro, José Ignacio (2000): El mapa topográfico del Protectorado de Marruecos en su contexto político e institucional (1923-1940), Documents d'Anàlisi Geogràfica, no 36, 2000, pp. 15-46. Los párrafos que siguen resumen de modo muy apretado su contenido.
} 
las cuales tiene un desarrollo de 60 minutos centesimales en longitud y 40 en latitud. Para su publicación las hojas fueron divididas en ocho partes, denominadas octavos, con unas dimensiones de $58 \times 34 \mathrm{~cm}$, que tienen numeración e identificación nominal propia. Descartadas las zonas marítimas comprendidas en el recuadro de la carta, resultan un total de 117 octavos, que representan una superficie aproximada de 20.000 kilómetros cuadrados (ver figura 1).

FIGURA 1
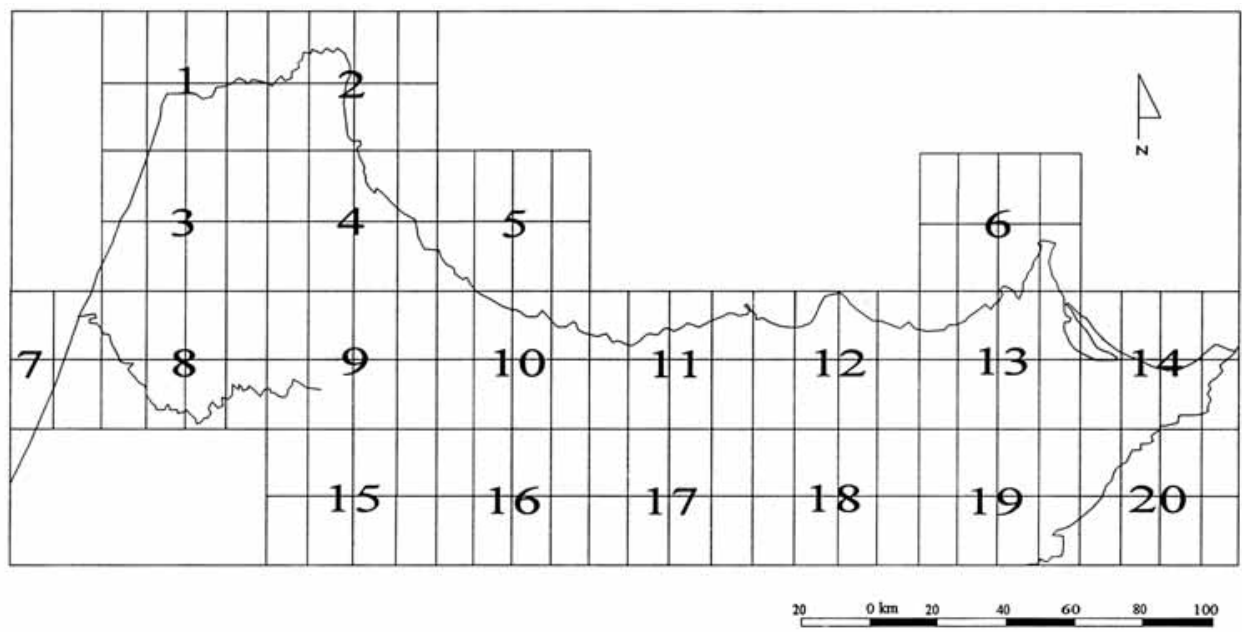

Cuadro de distribución de las hojas del Mapa topográfico del Protectorado de Marruecos a escala 1:50.000. Cada una de las hojas está dividida en ocho «octavos», con identificación nominal propia.

Fuente: Nadal, Urteaga y Muro, 2000.

En el levantamiento del mapa se emplearon dos técnicas diferentes: la taquimetría clásica, en los lados oriental y occidental del Protectorado, y la fotogrametría terrestre, en la zona más abrupta del Rif. La combinación de ambas técnicas, que constituía una novedad en la tradición cartográfica del Cuerpo de Estado Mayor, contribuye a explicar la rápida ejecución de un levantamiento realizado sobre un territorio muy accidentado y en buena parte desconocido (Muro, Nadal y Urteaga, 2002). La fotogrametría terrestre se empleó, como sistema exclusivo, en el levantamiento de 24 octavos. En 14 se combinó 
la taquimetría con la fotogrametría. Los 79 restantes se levantaron por taquimetría clásica.

Además de ejecutar el levantamiento topográfico, la Comisión Geográfica de Marruecos se encargó del cálculo y dibujo de las minutas del mapa, que se realizaban a escala 1:20.000, con representación de la altimetría mediante curvas de nivel equidistantes diez metros. Terminadas las minutas se remitían a Madrid, donde se efectuaba la labor de revisión, encuadre y rotulación final de las hojas. La tirada y publicación del mapa se efectuaba en los Talleres del Ministerio de la Guerra, empleando la impresión cromolitográfica a cinco colores.

El proceso de edición se inició en 1927, y fue muy vivo en los primeros años, ya que pudieron aprovecharse materiales reunidos por la propia Comisión Geográfica de Marruecos en los tres lustros anteriores. En 1931 se había publicado ya 80 octavos de los 117 previstos. En los años siguientes prosiguió con regularidad el levantamiento de la carta, si bien a un ritmo menor. Las hojas que faltaban por levantar correspondían a la zona meridional, fronteriza con el Protectorado de Francia. La existencia de un litigio sobre los límites fronterizos, que será tratado en un próximo apartado, retrasó el levantamiento de algunas de estas hojas. Por otra parte, la impresión del mapa planteó un problema específico. El decreto de 28 de julio de 1931, sobre reorganización de la actividad cartográfica, había asignado al Instituto Geográfico y Catastral la responsabilidad completa en materia de publicación de mapas. Sin embargo, dado que la edición del Mapa del Protectorado de Marruecos estaba ya muy avanzada, la Sección Cartográfica del Estado Mayor se dirigió de inmediato al Gobierno, solicitando que la tirada del mapa continuase haciéndose en los Talleres del Ministerio de la Guerra, a fin de mantener la uniformidad de toda la serie en lo que respecta a sombreado y color. En abril de 1932 el Gobierno autorizó que la tirada del mapa prosiguiese ejecutándose en el Ministerio de la Guerra y la edición siguió a un ritmo regular de seis octavos por año (figura 2).

El 11 de abril de 1936 el teniente coronel Aresio Viveros pudo remitir un telegrama desde Ceuta dando cuenta de que «había quedado finalizado en todas sus partes» el mapa 1:50.000 (Estado Mayor Central, 1947). Unas pocas hojas, cuyo dibujo final ya estaba concluido, quedaron en la imprenta debido al estallido de la guerra civil, y la tirada no se realizó hasta 1940.

Además del trabajo al que acabamos de aludir, la Comisión Geográfica de Marruecos acometió otros levantamientos a gran escala en respuesta a demandas específicas de las autoridades militares del Protectorado. Entre ellos cabe destacar los planos de campos de tiro y de maniobras. En julio de 1931 el jefe de las Fuerzas Militares de Marruecos comunicó a Federico Montaner Canet la conveniencia de efectuar diversos levantamientos a escala 1:5.000 de las zonas 
FIGURA 2

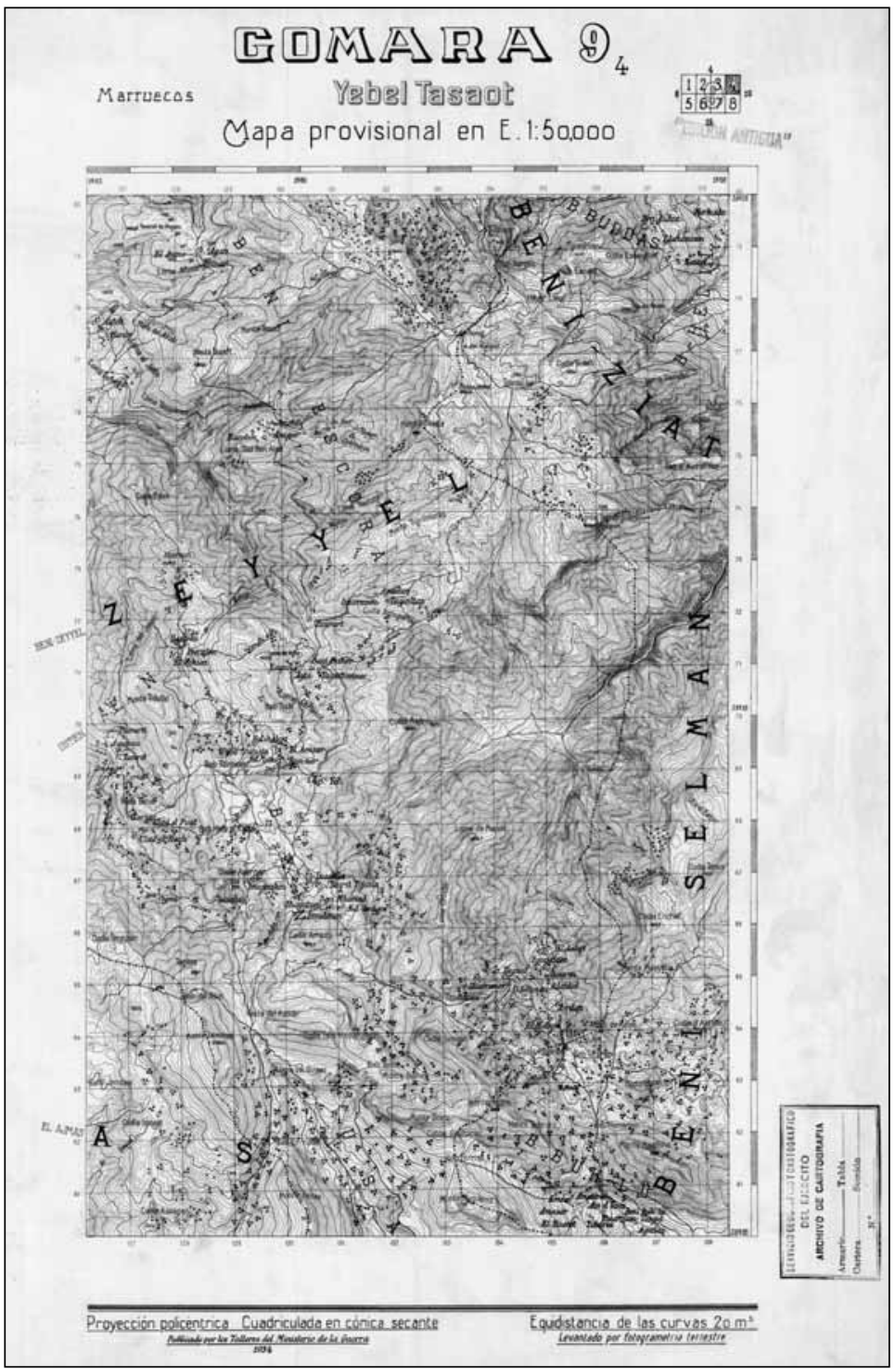

Marruecos. Mapa provisional en escala 1:50.000. Gomara. Hoja 9-4. Yebel Tasaot. Esta hoja constituye uno de los octavos levantados mediante fotogrametría terrestre. Fue editada en los Talleres del Ministerio de la Guerra en 1934

Fuente: Cortesía del Centro Geográfico del Ejército.

Estudios Geográficos, Vol. LXXI, 268, pp. 267-297, enero-junio 2010 ISSN: 0014-1496, eISSN: 1988-8546, doi: 10.3989/estgeogr.0453 
próximas a las guarniciones para preparar ejercicios de pequeñas unidades (Estado Mayor Central, 1947, 145). Este es el origen de los grandes planos de las inmediaciones de Tetuán ${ }^{10}$ y Castillejos ${ }^{11}$, levantados a escala 1:5.000 en 1932, y también de los planos de los campos de instrucción de Segangan (1934), Xauen (1934) y Beni Sidel (1935). A la misma escala, pero con curvas de nivel equidistantes dos metros, se dibujó el Plano del campo de tiro de Zadina ${ }^{12}$.

Una mención aparte merecen los trabajos que no tenían un carácter militar, sino que respondían a demandas de organismos de la administración civil encargados de la colonización agraria. Este es el caso de los planos de perímetros de colonización. El 1 de junio de 1929 se había establecido un procedimiento de catalogación y deslinde de bienes Majzen y de las colectividades indígenas, con el fin de ampliar las tierras de labor y asignar lotes a los colonos. Las operaciones técnicas de deslinde, que incluían el levantamiento de planos topográficos de los perímetros de colonización a escala 1:10.000 (y en algunos casos a escalas 1:1.000 y 1:2.000), fueron encomendadas por la Dirección de Colonización del Protectorado a la Comisión Geográfica de Marruecos en enero de $1930^{13}$. Los trabajos topográficos se iniciaron ese mismo año, y no fueron interrumpidos por la llegada de la República. A lo largo de 1931 se efectuó el levantamiento de los perímetros de colonización de Mehasen (8.400 hectáreas) ${ }^{14}$, Tzahadartz (5.070 hectáreas) ${ }^{15}$ y Buferrach (1.300 hectá-

10 Plano de las inmediaciones de Tetuán. Para el desarrollo de ejercicios de guarnición. Escala 1:5.000. Equidistancia entre curvas 5 metros. Ceuta, julio de 1932. El T. Coronel de E. M. Jefe. [Firmado]: Federico Montaner. 6 hojas manuscritas de $73 \times 54 \mathrm{~cm}$ Editado por los Talleres del Ministerio de la Guerra en 1934. CGEM (Ar25-1-2-102).

11 Plano de los alrededores de Castillejos. Para el desarrollo de ejercicios de guarnición. Comisión Geográfica de Marruecos. Escala 1:5.000. Equidistancia entre curvas, 5 metros. Cuatro hojas manuscritas, tinta china sobre papel vegetal: Hoja 1, $74 \times 66 \mathrm{~cm}$; Hoja 2, $73 \times 55 \mathrm{~cm}$; Hoja 3, $73 \times 55$ cm; Hoja 4, $73 \times 55 \mathrm{~cm}$ Ceuta, julio 1932. El T. Coronel de E. M. Jefe. [Firmado]: Federico Montaner. Impreso en los Talleres del Depósito de la Guerra en 1935. CGEM (Ar25-T1-C1-380).

12 Plano del campo de tiro de Zadina. Fuerzas Militares de Marruecos. Circunscripción de Ceuta-Tetuán. Escala 1:5.000. Equidistancia entre curvas 2 metros. Formado por la Comisión Geográfica de Marruecos del Cuerpo de E. M. Año de 1933. 1 hoja manuscrita de $45 \times 56 \mathrm{~cm}$ Impreso en los Talleres del Ministerio de la Guerra en 1935. CGEM (Ar24-T10-C2-329).

13 Carta del Director de Colonización al coronel Aranda, Tetuán, 9 de enero de 1930. CGEM, Leg. 156.

${ }^{14}$ Perímetro de colonización de Mehasen (Jolot). Comisión Geográfica de Marruecos, 1931. Polígono de 8.400 hectáreas. Terrenos del Majzén. Reproducido en Comisión Histórica de las Campañas de Marruecos, 1936, II, 416.

15 Perímetro de colonización de Tzahadartz (Garbia, Yebel Hebib y Beni Mesauar). Comisión Geográfica de Marruecos, 1931. Polígono de 5.070 hectáreas. Terrenos del Majzén. Reproducido en Comisión Histórica de las Campañas de Marruecos, 1936, II, 414.

Estudios Geográficos, Vol. LXXI, 268, pp. 267-297, enero-junio 2010 ISSN: 0014-1496, eISSN: 1988-8546, doi: 10.3989/estgeogr.0453 
reas) ${ }^{16}$. Con posterioridad, las operaciones topográficas relacionadas con la colonización agraria del Protectorado fueron encomendados a los topógrafos del Instituto Geográfico y Catastral.

También responde a una petición específica de la administración civil, en este caso de una junta vecinal local, la formación del plano del término de Targuist, una pequeña población enclavada en el corazón del Rif, que tuvo un rápido crecimiento a partir de 1927. En julio de 1934 la junta vecinal de Targuist se dirigió a la Comisión Geográfica de Marruecos solicitando que se efectuase el levantamiento del poblado y de su término municipal. Montaner Canet, entonces al mando de la comisión, indicó que no sería posible iniciar el levantamiento de inmediato, debido a la escasez de personal. La tarea pasó a manos de su sucesor, el teniente coronel Aresio Viveros, quien a comienzos de 1935 envió una sección a Targuist, con el fin de efectuar un levantamiento del término a escala 1:2.000, con representación del relieve mediante curvas equidistantes dos metros. Los trabajos de campo fueron concluidos el 25 de abril de $1935^{17}$, y el plano quedó inédito (ver figura 3).

En definitiva, la sección Geográfica no muestra ningún síntoma de parálisis o de estrangulamiento durante en el período 1931-1936. Al revés, la unidad mantuvo una actividad regular en su principal cometido, el levantamiento del mapa topográfico del Protectorado a escala 1:50.000. Paralelamente, desarrolló una enérgica labor en la realización de otros levantamientos a gran escala solicitados tanto por la administración civil como por las autoridades militares del Protectorado. Como veremos, casi otro tanto puede decirse de la sección de Límites integrada en la Comisión de Marruecos.

\section{LOS TRABAJOS DE LA SECCIÓN DE LÍMITES}

La sección de Límites tenía la misión de efectuar el levantamiento topográfico de la zona fronteriza de los Protectorados de Francia y España y formar un documento cartográfico único y fiable, que sirviese de base al deslinde definitivo de las zonas respectivas de protectorado. El convenio hispano-fran-

16 Perímetro de colonización de Buferrach (Sahel y Garbia). Comisión Geográfica de Marruecos, 1931. Polígono de 1.300 hectáreas. Plano reproducido en Comisión Histórica de las Campañas de Marruecos, 1936, II, 413.

17 Targuist. Campamento, poblado y término municipal. Escala 1:2.000. Equidistancia de curvas 2 metros. Año 1935. Formado por el Cuerpo de Estado Mayor. Comisión Geográfica de Marruecos. El Teniente Coronel de E. M. Jefe de la Comisión. [Firmado]: Aresio Viveros. 1 mapa sobre papel entelado de $80 \times 100 \mathrm{~cm}$ CGEM (Ar24-T10-C2-328). 
FIGURA 3

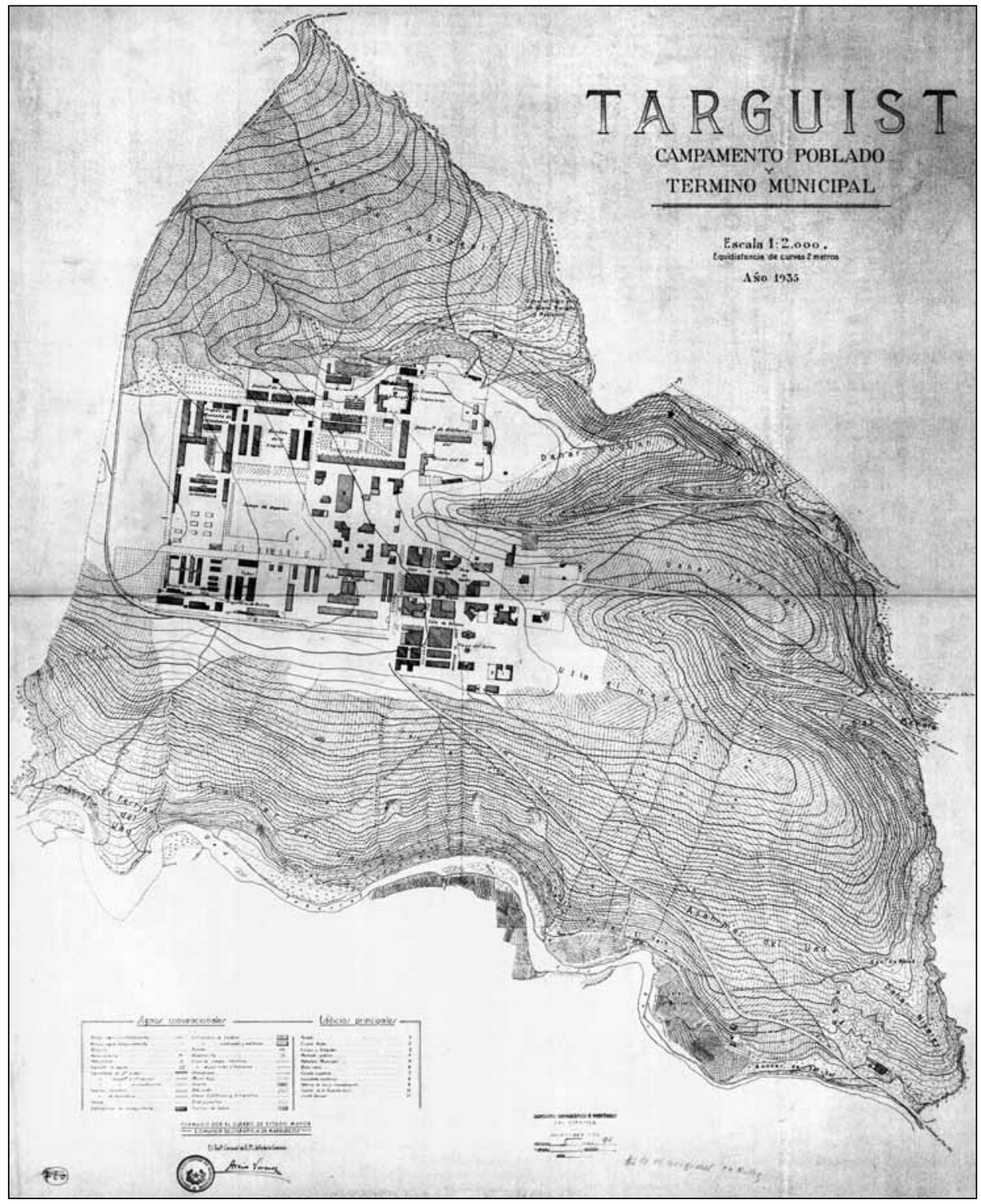

TArguist. Campamento, poblado y término municipal. Escala 1:2.000.

Un ejemplo de plano urbano levantado por la Comisión Geográfica de Marruecos en 1935 Fuente: Cortesía del Centro Geográfico del Ejército.

Estudios Geográficos, Vol. LXXI, 268, pp. 267-297, enero-junio 2010

ISSN: 0014-1496, eISSN: 1988-8546, doi: 10.3989/estgeogr.0453 
cés de 1912 en el que se acordó la formación del Protectorado español de Marruecos, se había redactado sin disponer de ningún mapa preciso de la zona (Urteaga, 2006a y 2006b). El convenio estableció un trazado fronterizo aparentemente fácil en los extremos oriental y occidental del territorio, y francamente complicado en el resto. En el extremo oriental la frontera debía seguir el curso del río Muluya hasta alcanzar Mexera Kelila (vado el Kelila). El Muluya, con su caudal permanente, resultaba un límite aparentemente fácil de deslindar. En la zona occidental, la frontera debía seguir el paralelo 35 grados norte hasta alcanzar el curso del río Lucus, muy cerca de Alcazarquivir. El extenso sector intermedio entre el curso del Lucus y el Muluya, de más de 300 kilómetros de desarrollo lineal, en cambio, quedó muy pobremente definido en el convenio, con una redacción confusa, y sin ningún tipo de respaldo cartográfico $^{18}$. Su deslinde iba a ser, en consecuencia, una fuente continua de problemas.

El curso de las operaciones militares contribuyó a complicar aún más las cosas. En efecto, el trazado fronterizo que se había acordado en 1912 se modificó de facto en numerosos puntos durante la guerra del Rif de 1921 a 1926. En el curso de la guerra las tropas francesas penetraron en la zona española y establecieron posiciones defensivas al norte del río Uarga. Esta ocupación, que inicialmente debía tener carácter provisional, adquirió un carácter definitivo tras el acuerdo firmado en Madrid entre los gobiernos de Francia y España el 25 de junio de 192519. El citado acuerdo dejó en zona francesa la cábilas de Marnissa, Beni Bucelama, Fernassa, Beni Uanyel, Metiua, y parte de la cábila de Beni Zerual. En la campaña subsiguiente al desembarco de Alhucemas de agosto de 1925, surgieron nuevos puntos de litigio en las cábilas de Beni Buyahi, Gueznaya y Beni Zerual, en las que el ejército francés estableció y mantuvo posiciones avanzadas en áreas reclamadas por España (ver figura 4).

Para tratar de solventar estos problemas fronterizos se negoció un nuevo acuerdo diplomático, firmado en París el 10 de julio de 1926, en el que se decidió reanudar de inmediato los trabajos de deslinde, iniciándolos en el sector fronterizo que se extendía desde el río Muluya hasta el Yebel Rokdi, un sector

\footnotetext{
18 Convenio entre España y Francia, celebrado el 27 de noviembre de 1912, para precisar la situación respectiva de los dos países con relación al Imperio xerifiano, en Diccionario de la Administración Española. Apéndice de 1913, Madrid, Imprenta del Asilo de Huérfanos, 1913, pp. 170-176.

19 Acuerdo de 25 de julio de 1925 entre España y Francia, relativo al límite de las dos zonas de influencia española y francesa en Marruecos. AMAE, Fondo Renovado. Leg. 3.846, Exp. 27. 
FIGURA 4

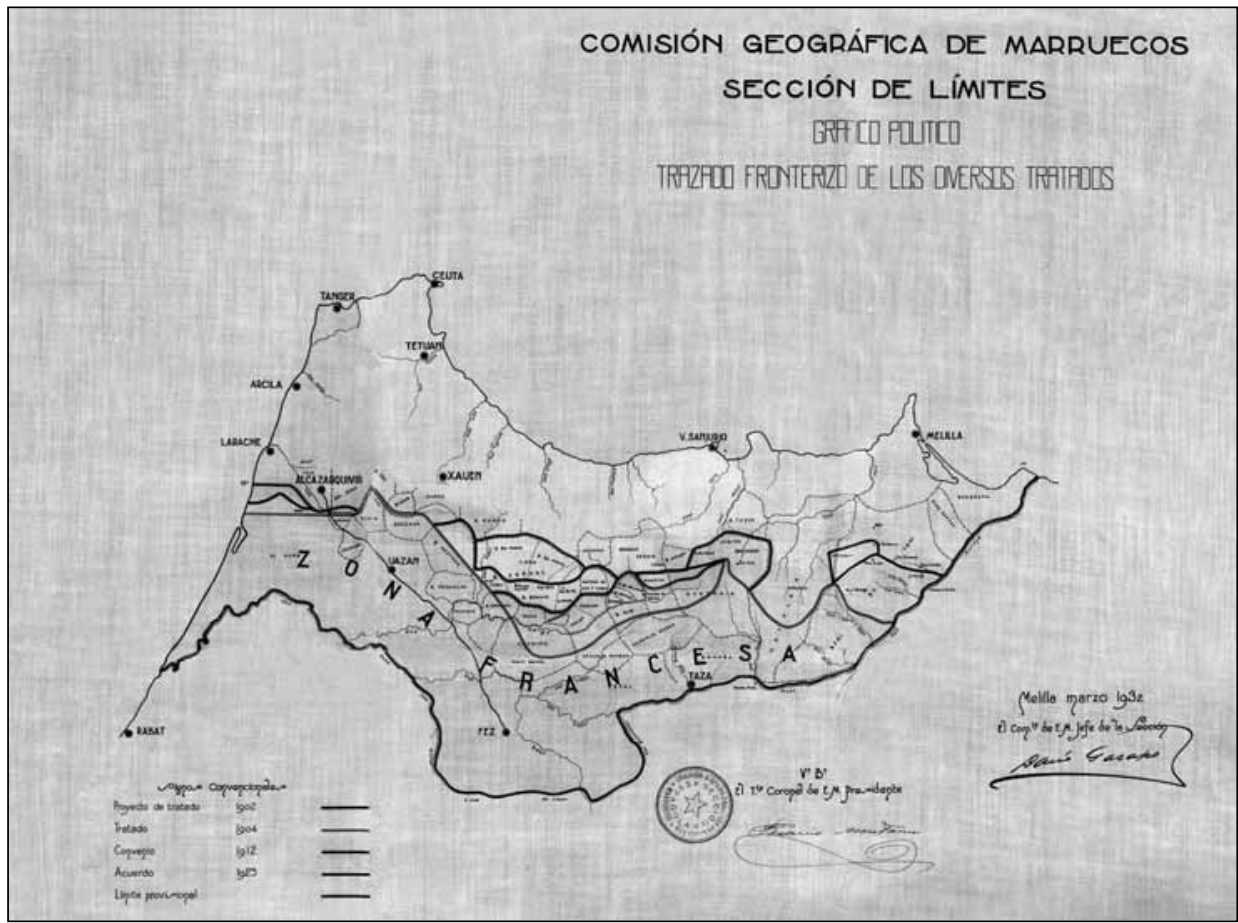

Gráfico político. Trazado fronterizo de los diversos tratados. Formado por la Sección de Límites de la Comisión Geográfica de Marruecos. Melilla, marzo 1932. Manuscrito a color sobre papel vegetal, $65 \times 41 \mathrm{~cm}$. Sin escala. [1:1.000.000]. El gráfico representa los trazados fronterizos acordados en 1904, 1912 y 1925, y los limites de hecho establecidos a partir de 1926

Fuente: Cortesía del Archivo del Ministerio de Asuntos Exteriores y Cooperación.

que por entonces estaba pacificado ${ }^{20}$. A tal efecto, el Ministerio de la Guerra decidió reforzar la sección de Límites, que quedó bajo el mando directo del jefe de la Comisión Geográfica de Marruecos, y desplazar la sede de la unidad a Melilla, para estar más próxima a la zona de operaciones. Desde 1927 la sec-

${ }^{20}$ Acuerdo relativo a la pacificación de Marruecos y al establecimiento de un régimen en los confines entre las zonas de influencia española y francesa. Firmado en París el día 10 de julio de 1926. AMAE, Fondo Renovado. Leg. 3.846, Exp. 27.

Estudios Geográficos, Vol. LXXI, 268, pp. 267-297, enero-junio 2010 ISSN: 0014-1496, eISSN: 1988-8546, doi: 10.3989/estgeogr.0453 
ción de Límites estaba integrada por el comandante de Estado Mayor Darío Gazapo Valdés ${ }^{21}$, el capitán del mismo cuerpo Rafael Gómez Redondo, y el comandante de Infantería Jesús Jiménez Ortoneda, el veterano africanista al que ya hemos aludido. En 1931 el capitán de Estado Mayor Carmelo Medrano Ezquerra substituyó a Rafael Gómez Redondo, que había ascendido a comandante de Estado Mayor.

El levantamiento topográfico de la franja fronteriza se reinició en 1927 en el vado de Saf-Saf, en el curso del Muluya, y prosiguió hacia el oeste hasta alcanzar el Yebel Rokdi en 1932, con un desarrollo de unos 200 kilómetros de longitud. En el curso de las operaciones se fijaron los vértices correspondientes a la triangulación de primer, segundo y tercer orden, y se procedió al relleno por el sistema de itinerarios taquimétricos. El trabajo de relleno se efectuó a escala 1:20.000, observándose un promedio de 40 puntos por kilómetro cuadrado en las zonas pobladas y unos 25 en las restantes.

Las operaciones resultaron bastante más lentas y complejas de lo esperado. Los cartógrafos españoles pretendieron inicialmente ceñir sus trabajos a una faja de doce kilómetros de anchura a caballo de la frontera concertada en el convenio de 1912 (Montaner Canet, 1932). La sección francesa de la Comisión de Límites, por el contrario, exigió levantar también la línea fronteriza acordada en 1925, y asimismo la fijada de hecho desde 1926. Tras una engorrosa negociación, se acordó que el levantamiento cubriese toda la extensión de terreno comprendida entre la línea del convenio de 1912 y la frontera real establecida al final de las operaciones militares. En consecuencia, hubo de ejecutarse un levantamiento mucho más amplio del previsto, sin que el objetivo de deslinde fronterizo avanzase ni un centímetro.

La multiplicación del trabajo de los cartógrafos constituye un simple reflejo de las tensiones existentes entre los gobiernos de Francia y España a propósito de Marruecos. El desacuerdo no era de carácter técnico, sino político. Dada la morfología de la cordillera del Rif, resultaba prácticamente imposible, con los medios de la época, construir una vía de comunicación este-oeste siguiendo la vertiente mediterránea de la cadena rifeña. La única posibilidad de

${ }^{21}$ Darío Gazapo Valdés (1891-1942) nació en La Habana, donde su padre era comisario de Guerra. Ingresó en la Academia de Infantería en 1907, formando parte de la misma promoción que el general Francisco Franco Bahamonde. Tras obtener el grado de teniente, fue destinado a Larache en 1916, realizando prácticas como cartógrafo militar en la Comisión Geográfica de Marruecos. Desde allí regresó España, para trabajar en la Comisión Geográfica del Nordeste hasta 1927. En julio de aquel año, siendo ya capitán, fue destinado de nuevo a la plantilla de la Comisión Geográfica de Marruecos y Límites. AGMS, Leg. 2.131. Ver también Urteaga, 2007. 
establecer una comunicación transversal dentro del Protectorado español estribaba en controlar las alturas que dominan la vertiente meridional del Rif. En consecuencia, la ampliación de la zona francesa al norte del Uarga entrañaba mucho más que una sensible pérdida territorial para los intereses españoles. Arruinaba la posibilidad de establecer una comunicación militar eficiente (Rodríguez, 1932).

Los esfuerzos diplomáticos españoles para reconducir la situación, continuos desde 193022, chocaron con la resistencia de Francia a abandonar una situación estratégica que les resultaba cómoda y ventajosa. La ocupación militar francesa en las cábilas de Beni Buyahi, Gueznaya y Beni Zerual se mantuvo, sin que la diplomacia encontrase un camino para resolver el litigio. En consecuencia, no fue posible proceder al deslinde de la frontera. Y ni siquiera pudieron proseguirse los trabajos topográficos fronterizos al oeste del Yebel Rokdi. El 2 de junio de 1932 los responsables del Ministerio de Estado ordenaron desde Madrid que en las hojas fronterizas del Mapa topográfico del Protectorado de Marruecos a escala 1:50.000 se hiciese constar la siguiente nota, que respondía parcialmente a la verdad: «No comprende la totalidad del territorio que corresponde al Protectorado español, a causa de no haberse podido realizar con anterioridad a la fecha de su publicación las operaciones topográficas para la delimitación de las zonas Española y Francesa»23.

Las dificultades para lograr un acuerdo diplomático entre Francia y España hubieran podido dejar sin objeto a la sección de Límites de la Comisión Geográfica de Marruecos. Sin embargo, las operaciones realizadas por el ejército francés en el sur de Marruecos cambiaron de nuevo el escenario. En 1933 y 1934 el ejército colonial francés llevó a cabo una enérgica ofensiva en el valle del Sus, que consiguió sofocar las últimas bolsas de resistencia bereber. La victoria francesa abrió una nueva etapa en la penetración colonial española en África occidental, ya que hizo posible la ocupación del territorio de Ifni.

22 Nota del Director General de Marruecos y Colonias, Dámaso Berenguer, al Embajador de España en París, sobre continuación de los trabajos de la Comisión de Límites en Marruecos, 14 de mayo de 1930. AMAE, Fondo Renovado. Leg. 394, Exp. 9. Y también Informe del Director General de Marruecos y Colonias al Ministro de Estado sobre límites de Marruecos, 6 de julio de 1932. AMAE, Fondo Renovado. Leg. 3.846, Exp. 27.

23 Nota del Director de Asuntos Políticos del Ministerio de Estado al Director General de Marruecos y Colonias, 2 de junio de 1932. AMAE, Fondo Renovado. Leg. 887, Exp. 24. 
EL MAPA DE IFNI

La pretensión de ocupar el enclave de Ifni venía de lejos. Entre las diversas concesiones arrancadas al gobierno marroquí tras la guerra de Tetuán de 185960 figuraba el establecimiento de una pesquería en la costa occidental de Marruecos. El artículo octavo del Tratado de Tetuán, firmado el 26 de abril de 1860 establecía que «S. M. Marroquí se obliga a conceder a perpetuidad a S. M. Católica, en la costa del Océano, junto a Santa Cruz de Mar Pequeña, el territorio suficiente para la formación de un establecimiento de pesquería como el que España tuvo allí antiguamente» 24 . Ni en el momento en que se negoció el tratado, ni en las décadas siguientes, pudo precisarse cual podría ser la localización de Santa Cruz de Mar Pequeña, una pequeña y efímera fortificación levantada en 1476, que había quedado abandonada hacia 1524. Esto no impidió que el gobierno de España, tras un simulacro de exploración geográfica llevado a término en la octava década del siglo XIX, diese por bueno que la desembocadura del uad Ifni era la localización exacta de la antigua factoría de Santa Cruz de Mar Pequeña (cf. Urteaga, 2006b). El persistente desacuerdo con el gobierno de Marruecos respecto a la localización de la factoría fue uno de los factores que impidió su toma de posesión durante el ochocientos.

El convenio hispano-francés de noviembre de 1912 se negoció, en lo que respecta a Ifni, casi en la misma situación de ignorancia geográfica que se tenía en 1860 (cf. Figueras, 1911). Baste señalar que las negociaciones diplomáticas se llevaron a término teniendo como respaldo cartográfico la edición de 1908 de la Carte du Maroc de R. de la Flotte de Roquevaire a escala 1:1.000.00025. Se trata de un mapa plagado de errores, formado originalmente en 1897 a partir de la compilación de fuentes diversas, y con una escala totalmente inadecuada para la fijación de fronteras. España mantuvo ante Francia la pretensión de que Ifni era el lugar de Santa Cruz de Mar Pequeña, y los negociadores del acuerdo dieron un paso más al asignar unos límites concretos al territorio de Ifni: «al Norte, el uad Bu Sedra, desde su desembocadura; al Sur, el uad Num, desde su desembocadura; al Este, una línea que diste aproximadamente veinticinco kilómetros de la costa» 26 . En definitiva, la concesión

${ }^{24}$ Tratado de paz y amistad firmado en Tetuán el 26 de abril de 1860. Reproducido en Cagigas, 1952, pp. 41-44.

25 Nota del Ministro de Estado, García Prieto, al Embajador de Francia en Madrid, 27 de mayo de 1912. AMAE, Fondo Renovado. Leg. 3.846, Exp. 28.

${ }_{26}$ Convenio entre España y Francia, celebrado el 27 de noviembre de 1912, para precisar la situación respectiva de los dos países con relación al Imperio xerifiano, en Diccionario de la 
arrancada a Marruecos en 1860 de un territorio para la formación de un establecimiento de pesquería, se transformó, fruto de los pactos coloniales, en un enclave de algo más de 2.000 kilómetros cuadrados, emplazado como una cuña en el Protectorado francés. En el mismo convenio se especificaba que una comisión técnica designada por los gobiernos de Francia y España se encargaría, llegado el caso, de fijar el trazado exacto de los límites indicados.

Ahora bien, el reparto de Marruecos fue más fácil de establecer sobre el papel que de traducir a la realidad. Los sucesivos intentos de España para ocupar Ifni, llevados a término en 1916, en 1919, en 1921 y, de nuevo, en 1933, fracasaron ante la resistencia de las cabilas de los Ait-bu-Amaran (Morales Lezcano, 2006). Finalmente, en abril de 1934, y en la estela de los avances militares franceses, un destacamento español, mandando por el coronel Osvaldo Capaz Montes, pudo tomar posesión del enclave. El problema del deslinde territorio se planteó de inmediato, y la razón es bien simple: los militares franceses y españoles desplazados a Ifni tomaron posiciones «cada cual donde llegó primero» (Lombardero Vicente, 1945, 50). Para empeorar la situación, el supuesto uad Bu Sedra, que debía marcar el límite norte del territorio de Ifni, no apareció por ningún lado: era un puro invento procedente de una cartografía tan imprecisa como fantasiosa (Commission franco-espagnole de délimitation de l'enclave d'Ifni, 1935).

Así las cosas, es comprensible que surgiesen incidentes por el control de las cabilas nómadas de Ifni. Los gobiernos de Francia y España reaccionaron con presteza ante los primeros incidentes fronterizos, y en mayo de 1934 procedieron al nombramiento de una comisión mixta, con el cometido específico de deslindar la frontera en Ifni. La delegación española en la Comisión de Límites de Ifni fue puesta bajo el mando del teniente coronel de Estado Mayor Carlos Noreña Echevarría ${ }^{27}$, y estaba integrada por el comandante de

Administración Española. Apéndice de 1913, Madrid, Imprenta del Asilo de Huérfanos, 1913, pp. 170-176.

27 Carlos Noreña Echevarría (La Habana, 1889-Madrid, 1936) ingresó en la Academia de Infantería de Toledo en 1904, graduándose como teniente en 1907. En 1909 fue destinado a Melilla donde tomó parte en diversas acciones de guerra. Regresó a la Península en 1910, para ingresar en la Escuela Superior de Guerra. Alcanzó el empleo de capitán de Estado Mayor en 1915, teniendo destinos sucesivos en Zaragoza y Madrid. En 1922, una vez ascendido a comandante de Estado Mayor, fue nombrado profesor de la Escuela Superior de Guerra, donde impartió clase hasta 1927. En julio de 1927 fue destinado a Larache, quedando adscrito al Estado Mayor de las fuerzas militares de Marruecos. Desde 1929 a 1931 siguió cursos en la Escuela Superior de Guerra de París. Nombrado teniente coronel en 1930, en octubre de 1931 quedó adscrito al Estado Mayor Central (AGMS, Leg. N-547). 
Estado Mayor Darío Gazapo Valdés, y el capitán de Infantería Antonio del Oro Pulido ${ }^{28}$. Paralelamente, se procedió al nombramiento de una sección cartográfica anexa, que recibió el encargo de efectuar las operaciones astronómicas, geodésicas y topográficas necesarias para formar el mapa de Ifni y proceder al deslinde fronterizo. La dirección de esta sección de carácter técnico, integrada por cartógrafos procedentes de la Comisión Geográfica de Marruecos, se confió al comandante Manuel Lombardero Vicente, que se había encargado de las operaciones geodésicas del Mapa del Protectorado a escala 1:50.000 (ver cuadro 2).

\section{Cuadro 2}

ORGANIZACIÓN Y PERSONAL DE LA DELEGACIÓN ESPAÑOLA EN LA COMISIÓN DE LÍMITES DE IFNI (1934-1935)

\begin{tabular}{ll}
\hline Comisión de Límites & $\begin{array}{l}\text { Teniente coronel de Estado Mayor Carlos Noreña Echevarría } \\
\text { Comandante de Estado Mayor Darío Gazapo Valdés } \\
\\
\text { Capitán de Infantería Antonio de Oro Pulido }\end{array}$ \\
Sección cartográfica & $\begin{array}{l}\text { Comandante de Estado Mayor Manuel Lombardero Vicente } \\
\text { anexa }\end{array}$ \\
& Capitán de Estado Mayor Carmelo Medrano Ezquerra \\
& Capitán de Estado Mayor Antonio Gómez Goya
\end{tabular}

Fuente: AMAE, Fondo Renovado. Leg. 3.846, Exp. 28 y Estado Mayor Central, 1947.

Carlos Noreña y Darío Gazapo se reunieron con los delegados franceses en Rabat, el 16 de junio de 1934, para constatar lo obvio: la ausencia de documentos cartográficos precisos hacía impracticable la labor de deslinde. En consecuencia, los integrantes de la Comisión mixta acordaron aplazar las conversaciones hasta poder contar con el resultado de un levantamiento cartográfico a gran escala, y desplazarse a Ifni, con el fin de realizar un reconocimiento preliminar del territorio.

Los cartógrafos mandados por Lombardero Vicente ya les estaban esperando allí. El 14 de mayo de 1934 la Presidencia del Consejo había ordenado a la Comisión Geográfica de Marruecos que facilitase a la Comisión de Límites de Ifni el personal de apoyo, y el instrumental necesario, para llevar a término

28 Nota del Subsecretario de Presidencia del Consejo al Ministro de Estado, 3 de julio de 1934. AMAE, Fondo Renovado. Leg. 3.846, Exp. 28. 
los trabajos cartográficos requeridos. El personal de apoyo estaban integrado por un maestro de taller, seis cabos, cuatro soldados europeos y 10 askaris (soldados nativos) procedentes todos ellos de la Comisión de Marruecos. Además, quedarían agregados a la misma un teniente del Cuerpo de Ingenieros, cuatro soldados obreros para reparaciones, un sargento, un cabo y ocho conductores. En total el contingente que debía trasladarse a Ifni ascendía a medio centenar de personas. Para sus movimientos por territorio marroquí se les dotó con seis camionetas, dos coches ligeros, y un furgón rápido de media tonelada con repuesto de herramientas (Estado Mayor Central, 1947, 151).

El contingente citado salió para Ifni el 22 de mayo de 1934. Los jefes y oficiales en avión y el resto del personal en camioneta. Una parte del equipamiento se embarcó en el barco de transporte España 5. Cuando el navío llegó ante las costas de Ifni surgió un frustrante problema, que al parecer nadie había previsto cabalmente. No había, en toda la costa de Ifni, ningún tipo de instalaciones portuarias que facilitasen la carga y descarga directa de los barcos. En consecuencia, era imprescindible recurrir al barqueo para poder desembarcar. Las lanchas que se empleaban en los desembarcos debían pasar a remo la zona de rompientes, los días en que las olas lo permitían. A veces, durante semanas e incluso meses, ninguna embarcación conseguía efectuar la peligrosa operación de cruzar las rompientes (Caffarena, 1966). Esto es justamente lo que ocurrió durante los meses de junio y julio de 1934. El material embarcado en el España 5 no se pudo llevar a la playa de Ifni. El grupo de cartógrafos dirigidos por el comandante Lombardero Vicente debió conformarse con realizar un reconocimiento preliminar del territorio, que sirvió para la elección de la base de triangulación. En el mes de agosto se suspendieron los trabajos, por el calor, y también por la persistencia de los problemas de desembarque, y los comisionados abandonaron Ifni temporalmente (Lombardero Vicente, 1945, 52).

La frustrante experiencia inicial dio paso a una segunda tentativa, organizada durante el mes de septiembre de 1934. La sección de Ifni fue reforzada aumentando su dotación con un oficial de Estado Mayor, el capitán Antonio Gómez Goya, y un generoso equipo auxiliar: un sargento topógrafo, un cabo, ocho soldados y diez askaris más procedentes de la Comisión de Marruecos. Unidos al personal designado en mayo, la sección de Límites de Ifni contabilizaba ya 74 efectivos (Estado Mayor Central, 1947). Este personal salió de nuevo para Ifni en el España 5, en la madrugada del 19 de septiembre. El comandante Lombardero Vicente, y los capitanes Gómez Goya y Medrano Ezquerra lo hicieron el mismo día en trimotor.

Esta vez pudo efectuarse el desembarco en los primeros días del mes de octubre. A partir de ahí los trabajos evolucionaron con mucha rapidez. Manuel 
Lombardero Vicente se encargó de las determinaciones astronómicas, la medición de bases y la dirección de los trabajos de triangulación. Las operaciones geodésicas dieron lugar a la observación de casi 200 vértices trigonométricos, con una densidad de un vértice por cada 12 kilómetros cuadrados: en opinión del cartógrafo militar Manuel García-Baquero, se trata de una densidad adecuada para una buena triangulación de tercer orden (García-Baquero, 1966, 29). A continuación se efectuaron los trabajos topográficos de relleno, empleando para ello tres partidas de trabajo, que realizaban los croquis de campo a escala 1:50.000.

El 16 de enero de 1935 Carlos Noreña Echevarría comunicó al jefe del Estado Mayor Central que los trabajos cartográficos precisos para la delimitación habían quedado finalizados. Para entonces la Presidencia del Consejo de Ministros, a petición del teniente coronel José María Baigorri Aguado, jefe accidental de la Sección Cartográfica del Estado Mayor Central, había decidido ya que prosiguiese el levantamiento hasta completar todo el territorio a escala 1:50.00. Se trata de una decisión perfectamente razonable, toda vez que no existía cartografía de la zona realizada a gran escala y con garantías de precisión. A tal efecto, la sección mandada por el comandante Lombardero Vicente continuó en Ifni, efectuando los trabajos necesarios para el levantamiento total del territorio. En esta fase la sección pasó a depender directamente de la Comisión Geográfica de Marruecos (Estado Mayor Central, 1947, 153).

Al igual que había sucedido en la zona norte del Protectorado de Marruecos, la disponibilidad de mapas no puso fin al litigio fronterizo. La comisión mixta de Límites volvió a reunirse en Rabat el 15 de marzo de 1935. La delegación española estaba integrada por el teniente coronel Noreña, el comandante Gazapo y el capitán Antonio de Oro. Del lado francés tomaron parte el coronel Chardon, comandante del territorio de Ouarzazat, el capitán Lecomte, miembro del gabinete del Residente general, y el teniente intérprete Charles Dominique (Commission franco-espagnole de délimitation de l'enclave d'Ifni, 1935). Los comisionados lograron un rápido acuerdo sobre los límites teóricos del sur y del este de Ifni; sin embargo, el límite septentrional resultó un obstáculo insuperable. La delegación francesa identificó el uad Bu Sedra con el uad Salogmad, que alcanza el océano Atlántico por la bahía de Sidi Mohamed ben Abdallah. Los negociadores españoles rechazaron esta identificación, y pretendieron que el $\mathrm{Bu}$ Sedra era en realidad el uad Assif N'Tzouguart, que discurría mucho más al norte. El objetivo de Noreña, marcado desde Madrid, era dejar en territorio español a todas las cabilas de los Ait-Ba-Amaran. Pero este criterio de unidad etnográfica, que suponía una ampliación del territorio pactado en 1912, fue rechazado de plano por los negociadores franceses. Tras 
varias reuniones de tanteo, mantenidas durante la segunda quincena del mes de marzo, las posiciones siguieron donde estaban.

El fondo del asunto tenía poco que ver con el pequeño enclave de Ifni. El gobierno español habría negociado cualquier límite fronterizo en Ifni, siempre que Francia hubiera estado dispuesta a hacer concesiones en la zona norte del Protectorado de Marruecos. Sin embargo, la resistencia francesa a evacuar las cabilas de Gueznaya, Marnissa y Beni Zerual, condujo a la intransigencia española en el territorio de Ifni ${ }^{29}$. A la postre, la frontera quedó sin demarcar tanto en el norte como en el sur de Marruecos.

Pese a este fracaso diplomático, los trabajos cartográficos seguían su curso. El 8 de mayo de 1935 el jefe de la Comisión Geográfica de Marruecos informó a Madrid de la finalización de las operaciones de campo para el mapa de Ifni. A partir de entonces debían dar comienzo los trabajos de gabinete para la formación de la carta, cuya edición estaba prevista en ocho hojas a escala 1:50.000. Dado que las tareas de dibujo podían demorarse varios meses, el teniente coronel Aresio Viveros propuso la realización expeditiva de un croquis provisional a escala 1:100.000, que podría ser de utilidad en tanto no se concluyese el mapa definitivo. Su propuesta fue aprobada, y el 20 de mayo de 1935 se autorizó la formación del croquis de Ifni a escala 1:100.000, del cual debía hacerse una reproducción limitada a fin de proporcionar ejemplares al Alto Comisario y a las autoridades militares del territorio de Ifni (Estado Mayor Central, 1947, 153). La Comisión Geográfica de Marruecos se puso manos a la obra de inmediato, pero antes de que pudieran concluirse los trabajos la situación iba a dar un giro imprevisto.

\section{LA REORGANIZACIÓN DE LOS SERVICIOS DE CARTOGRAFÍA COLONIAL}

La finalización del mapa de Ifni está asociada a una decisión organizativa relativamente inesperada. El 12 de julio de 1935 la sección de Límites fue segregada de la Comisión Geográfica de Marruecos para dar lugar a una unidad independiente. La misión encomendada a la nueva unidad será efectuar los trabajos topográficos en las líneas fronterizas de diversas zonas de África en las que España ejercía jurisdicción. En adelante, los servicios de cartografía colonial quedaron divididos en dos unidades separadas que recibirán la denominación de Comisión Geográfica de Marruecos, con sede en Ceuta, y Comisión de Lími-

${ }^{29}$ Nota de la Alta Comisaría de España en Marruecos al Presidente del Consejo de Ministros, 30 de marzo de 1935. AMAE, Fondo Renovado. Leg. 3.846, Exp. 28.

Estudios Geográficos, Vol. LXXI, 268, pp. 267-297, enero-junio 2010

ISSN: 0014-1496, eISSN: 1988-8546, doi: 10.3989/estgeogr.0453 
tes de África, con sede en Melilla. El mando de la Comisión de Límites de África le fue conferido al comandante de Estado Mayor Darío Gazapo Valdés, que muy pronto ascendería a teniente coronel. El teniente coronel Aresio Viveros retuvo la responsabilidad sobre la Comisión Geográfica de Marruecos (ver cuadro 3).

\section{CuAdro 3}

ORGANIZACIÓN Y PERSONAL DE LOS SERVICIOS DE CARTOGRAFÍA COLONIAL (1935-1936)

\begin{tabular}{ll}
\hline Comisión Geográfica de Marruecos & Comisión de Límites de África \\
Teniente coronel Aresio Viveros Gallego & Teniente coronel Darío Gazapo Valdés \\
Comandante Félix Pérez Gluck (1) & Comandante Manuel Lombardero Vicente (5) \\
Comandante José Millán Díaz & Capitán Carmelo Medrano Ezquerra \\
Comandante José M. Duque Sampayo (2) & \\
Capitán Aurelio Matilla Jimeno (3) & \\
Capitán Antonio Gómez Goya (3) & \\
Capitán José Ruiz-Fornells Ruiz & \\
Capitán Juan Cerdá Marqués (4) & \\
\hline
\end{tabular}

(1) Destinado a la Península el 27-3-1936. (2) Destinado a la Comisión de Marruecos el 29-4-1936. (3) Destinado a la Península por ascenso a comandante de Estado Mayor en febrero de 1936. (4) Destinado a la Comisión de Marruecos el 10-5-1936. (5) En comisión durante 1935. Fuente: Elaboración propia a partir de Anuario Militar de España, 1935-1936, y expedientes personales del AGMS.

No hemos podido encontrar ninguna explicación satisfactoria para esta duplicación de organismos, llevada a término en un momento de restricciones presupuestarias. Como ya se ha indicado, los trabajos de demarcación estaban paralizados tanto en la zona norte del Protectorado como en Ifni, debido a la oposición de Francia. Por otra parte, la experiencia de una dirección centralizada de todas las actividades cartográficas, puesta en práctica desde 1926, había dado buenos resultados. Una cosa es segura: la decisión no le sentó nada bien al teniente coronel Aresio Viveros Gallego.

El divorcio fue bastante traumático. A finales de julio de 1935 Darío Gazapo Valdés solicitó al jefe de la Comisión Geográfica de Marruecos la entrega de los trabajos de campo y gabinete correspondientes al mapa de Ifni. El teniente coronel Aresio Viveros Gallego se resistió a entregar los materiales del mapa, y escribió a Madrid, alegando que la fase de trabajo de gabinete estaba ya próxima a su conclusión. En Madrid, el jefe accidental de la Sección Cartográfica del Estado Mayor, el teniente coronel César Voyer Méndez, aceptó los 
argumentos de Aresio Viveros, y propuso que la Comisión de Marruecos continuase encargada del mapa de Ifni. Sin embargo, el entonces jefe del Estado Mayor Central, el general Francisco Franco Bahamonde, no fue del mismo parecer. El 24 de agosto de 1935 Aresio Viveros Gallego debió hacer entrega al comandante Manuel Lombardero Vicente de todo lo relacionado con el levantamiento de Ifni (Estado Mayor Central, 1947).

A partir de ese momento el mapa de Ifni inició una peregrinación absurda. A finales de agosto Lombardero Vicente llevó los cuadernos de cálculo, los croquis de campo y las minutas del mapa desde Ceuta a Melilla. El 9 de septiembre de 1935 dos copias del croquis de Ifni viajaron de nuevo desde Melilla a Madrid, para servir de base a la impresión del mapa. Trascurrida una semana, los técnicos de los Talleres del Ministerio de la Guerra dictaminaron en Madrid que las copias del croquis de Ifni no eran adecuadas para proceder a la reproducción. En consecuencia, hubo que solicitar con urgencia el original a Melilla, que viajó a la capital el 22 de septiembre.

El Croquis del Territorio de los Ait-Ba-Amaran (Ifni) a escala 1:100.000 pasó finalmente a la imprenta del Ministerio de la Guerra en noviembre de 1935, realizándose una tirada de 500 ejemplares ${ }^{30}$. Se imprimió a cinco colores, con altimetría croquizada, en una hoja de $64 \times 83 \mathrm{~cm}$. El mapa incluye la cuadrícula Lambert, y las longitudes quedaron referidas al meridiano de Greenwich (ver figura 5).

Mientras tanto, las tensiones entre Aresio Viveros Gallego y Darío Gazapo Valdés a propósito de las atribuciones de sus respectivas unidades, seguían sin amainar. Uno de los puntos de discordia fue la asignación de instrumental y material perteneciente a la Comisión Geográfica de Marruecos, que debía ser separado y entregado a la Comisión de Límites. El reparto del material provocó incidentes, y requirió la intervención arbitral del jefe accidental de la Sección Cartográfica del Estado Mayor. Un segundo elemento de fricción, seguramente el más importante, fue la pretensión de Aresio Viveros Gallego de extender la actividad de la Comisión Geográfica de Marruecos a los territorios del Sahara y Guinea. A tal efecto, el 28 de julio de 1935 propuso al jefe de la Sección Cartográfica del Estado Mayor que la Comisión Geográfica de Marruecos cambiase su nombre por el de Comisión Geográfica del África Espa-

30 Croquis del Territorio de los Ait-Ba-Amaran (Ifni). Mapa provisional. Formado por la Comisión del Cuerpo de Estado Mayor. Noviembre 1935. Escala 1:100.000. Cuadrícula Lambert Sur Marruecos. Longitudes W. Greenwich. 1 hoja impresa en color de $64 \times 83 \mathrm{~cm}$ Editado por los Talleres del Ministerio de la Guerra. Al margen: «Por completar toponimia». Relieve por curvas de configuración. CGEM (Ar25-T3-C1-142). 


\section{FIGURA 5}

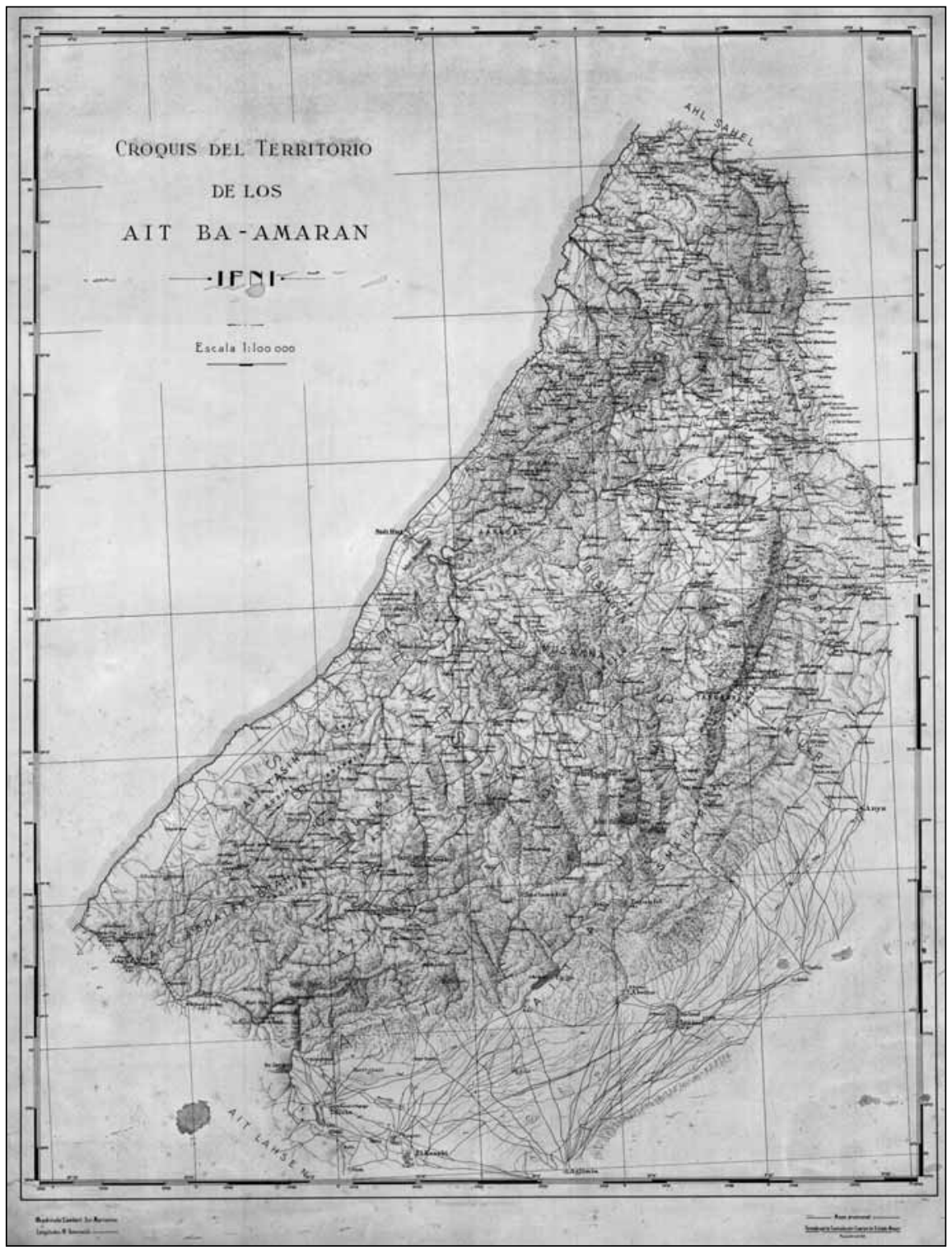

Croquis del Territorio de los Ait-Ba-Amaran (Ifni). Escala 1:100.000.

Editado en los Talleres del Depósito de la Guerra en noviembre de 1935

Fuente: Cortesía del Centro Geográfico del Ejército.

Estudios Geográficos, Vol. LXXI, 268, pp. 267-297, enero-junio 2010 ISSN: 0014-1496, eISSN: 1988-8546, doi: 10.3989/estgeogr.0453 
ñola (Estado Mayor Central, 1947, 154). La propuesta del teniente coronel Viveros Gallego pasó a informe de la $1^{\text {a }}$ Sección del Estado Mayor Central, que emitió un dictamen favorable el 29 de noviembre. Sin embargo, el 6 de diciembre de 1935 el general Francisco Franco resolvió en sentido contrario: la Comisión Geográfica de Marruecos debía mantener su nombre y su competencia exclusiva sobre territorio marroquí.

El teniente coronel Gazapo Valdés consideró que su posición había quedado reforzada, y volvió a reclamar más medios. El 17 de diciembre del mismo año solicitó que fuese asignado un grupo de apoyo procedente de la dotación de la Comisión Geográfica de Marruecos. La petición suponía condenar a la parálisis a la Comisión Geográfica, de modo que el Estado Mayor Central solicitó aclaraciones. ¿Qué planes de trabajo tenía la Comisión de Límites? ¿Cuál era la urgencia de los mismos? La respuesta llegó desde Melilla el 30 de enero de 1936: el proyecto estrella del teniente coronel Gazapo Valdés era, nada menos, la formación del mapa del Sahara. Para ello solicitaba dos topógrafos, dos dibujantes, siete cabos y 17 soldados (Estado Mayor Central, 1947, 157).

Esta vez la Sección Cartográfica del Estado Mayor optó por plantarse. El levantamiento del mapa del Sahara no figuraba entre las misiones asignadas a la Comisión de Límites de África, y, por otra parte, no tenía sentido llevar a la parálisis a la Comisión Geográfica de Marruecos restándole más personal. Las querellas internas fueron consumiendo unas energías que hubiera sido más provechoso destinar a otros menesteres. La unidad mandada por Aresio Viveros Gallego, como ya sabemos, logró concluir el levantamiento del mapa topográfico del Protectorado de Marruecos a escala 1:50.000 en el mes de abril de 1936. Por entonces el principal proyecto era el levantamiento del Plano Director de la zona del estrecho de Gibraltar a escala 1:20.000. Quedó pendiente. La principal tarea de la unidad mandada por el teniente coronel Gazapo Valdés era el dibujo final de las ocho hojas del Mapa del territorio de Ifni a escala 1:50.000. Tampoco llegó a concluirse. La insurrección militar de julio de 1936 paró en seco los trabajos cartográficos. El primer choque armado de la guerra civil tuvo lugar el 17 de julio, a las cinco de la tarde, precisamente en la sede de la Comisión de Límites de África.

\section{CONCLUSIONES}

Pese a las restricciones presupuestarias, la Segunda República continuó dedicando cuantiosos recursos, económicos y humanos, a la cartografía colonial. En realidad, el mayor empeño de la cartografía militar española durante la 
época fueron precisamente los levantamientos cartográficos acometidos en África. Los sucesivos gobiernos republicanos mantuvieron una fuerte continuidad, organizativa y funcional, en el ámbito de la cartografía colonial, sin que se detecte ningún cambio significativo respecto a los planes trazados durante la dictadura de Primo de Rivera. Excepto en los casos de ascenso, que daban lugar automáticamente a un cambio de destino, la República mantuvo en sus puestos a todos los jefes y oficiales destinados en la Comisión Geográfica de Marruecos.

Al igual que en etapas anteriores la actividad cartográfica siguió centrada en el territorio de Marruecos, y fue protagonizada por la Comisión Geográfica de Marruecos y Límites. Hasta donde hemos podido averiguar, no se registró ningún intento de extender los trabajos cartográficos al Sahara o a Guinea, al menos hasta 1936; en cualquier caso esos planes quedaron sobre el papel. Las realizaciones cartográficas más importantes del período fueron la culminación del mapa topográfico del Protectorado de Marruecos a escala 1:50.000, y el levantamiento del mapa de Ifni a la misma escala. Los dos mapas tienen un significado análogo: se trata de las primeras cartas precisas y a gran escala de aquellos territorios. Se trata, asimismo, de levantamientos cartográficos difíciles, realizados con premura, y sobre terrenos abruptos y desconocidos.

El esfuerzo paralelo dedicado a los trabajos de deslinde de la frontera de los Protectorados de España y Francia en Marruecos, y de la frontera de Ifni, no dio el resultado buscado. El problema no fue de naturaleza técnica, ya que los levantamientos topográficos de la zona fronteriza se llevaron a término sin dificultad. El obstáculo fue de carácter político. Tras una breve fase de convergencia, en 1925 y 1926, propiciada por la necesidad común de poner fin a la guerra del Rif, los intereses españoles y franceses volvieron a distanciarse en Marruecos. La resistencia del gobierno francés a abandonar las áreas ocupadas por sus tropas en las cabilas fronterizas de Beni Buyahi, Gueznaya y Beni Zerual, pudo haber sido el obstáculo esencial para alcanzar un acuerdo diplomático de carácter general. La imposibilidad para deslindar las fronteras revela, en cualquier caso, diferencias de fondo en las estrategias coloniales de Francia y España.

Recibido: $17 / 02 / 2009$

Aceptado: 29/04/2010 


\title{
FUENTES Y BIBLIOGRAFÍA
}

\author{
Abreviaturas \\ AGMS: Archivo General Militar de Segovia. \\ AMAE: Archivo del Ministerio de Asuntos Exteriores y de Cooperación. Madrid. \\ CGEM: Centro Geográfico del Ejército. Madrid.
}

\section{Fuentes inéditas}

Barroso, Antonio (1935): Informe sobre los territorios del sur de Marruecos por el comandante D. Antonio Barroso, agregado militar de la Embajada de España en París al Embajador de España en París, 26 de marzo de 1935, 21 pp. Mecanografiado. AMAE, Fondo Renovado. Leg. 967, Exp. 42.

Commision Franco-Espagnole de Delimitation de L'enclave D'Ifni (1935): Procès-verbal des réunions tenues a Rabat au mois de mars 1935, par la Commission francoespagnole de délimitation de l'enclave d'Ifni, 23 mars 1935. Mecanografiado, 8 pp. AMAE, Fondo Renovado. Leg. 3.846, Exp. 28.

Dirección de Colonización (1930): Instrucciones para la práctica de las operaciones técnicas de señalamiento de perímetros de Colonización y de deslinde de bienes Majzén y de las colectividades indígenas. Tetuán, 6 de enero de 1930. El Director de Colonización, Ángel de Torrejón. Conforme: Jordana. Rubricado. Mecanografiado, CGEM.

Dirección General de Marruecos y Colonias (1932): Informe del Director General de Marruecos y Colonias al Ministro de Estado sobre límites de Marruecos, 6 de julio de 1932. Mecanografiado, 3 folios. AMAE, Fondo renovado. Leg. 3.846, Exp. 27.

Estado Mayor Central. Servicio Geográfico del Ejército. Archivo de Mapas (1947): Comisión de Estado Mayor en Marruecos. Comisión mixta de delimitación Hispano-Francesa en Marruecos. Comisión Geográfica de Marruecos. Breves extractos de la documentación existente en el Archivo (desde el año 1881 a 1936). Mecanografiado, 160 pp. CGEM.

Figueras, Emilio (1911): Datos del Ministerio de Estado referentes a Santa Cruz de Mar Pequeña, Madrid, 6 de marzo de 1911. El Comandante de Estado Mayor, Comisionado. Manuscrito sin paginar. AGMS, Sección 2a , División 3ª Leg. 146.

Montaner Canet, Federico (1932): Informe que eleva a su excelencia el Alto Comisario de España en Marruecos, la Sección de Límites de la Comisión Geográfica de Marruecos. Ceuta, abril de 1932. El Teniente Coronel de Estado Mayor, Federico Montaner Canet, 8 pp. Mecanografiado. AMAE, Fondo Renovado. Leg. 3.846, Exp. 27.

Rodríguez, Rafael (1932): Informe del Jefe de Estado Mayor del General Jefe Superior de las Fuerzas Militares de Marruecos, coronel Rafael Rodríguez, al Alto Comisa- 
rio de Marruecos sobre Límites del Protectorado, 6 de julio de 1932. Mecanografiado. AMAE. Fondo Renovado. Leg. 3.846, Exp. 27.

\section{Bibliografía}

Alonso Baquer, M. (1972): Aportación militar a la cartografía española en la historia contemporánea. Madrid. Consejo Superior de Investigaciones Científicas, 365 pp.

Alpert, M. (1982): La reforma militar de Azaña. Madrid. Siglo xxi, 338 pp.

Balfour, S. (2002): Abrazo mortal. De la guerra colonial a la Guerra Civil en España y Marruecos (1909-1939). Barcelona. Península, 629 pp.

Caffarena Aceña, V. (1966): Las obras públicas en las provincias de Ifni y Sahara. Archivos del Instituto de Estudios Africanos. Madrid, no 78, pp. 73-90.

Cagigas, I. de las (1952): Tratados y convenios referentes a Marruecos, Madrid. Consejo Superior de Investigaciones Científicas. Instituto de Estudios Africanos, $506 \mathrm{pp}$.

Comisión Histórica de las Campañas de Marruecos (1935-1936): Geografía de Marruecos, Protectorados y Posesiones de España en África. Madrid. Ministerio de la Guerra. Tomo I, 1935; tomo II, 1936.

Convenio (1912): Convenio entre España y Francia, celebrado el 27 de noviembre de 1912, para precisar la situación respectiva de los dos países con relación al Imperio xerifiano, en Diccionario de la Administración Española. Apéndice de 1913. Madrid. Imprenta del Asilo de Huérfanos, 1913, pp. 170-176.

García-Baquero y Sáinz de Vicuña, M. (1966): Cartografía Militar Africana-Española. Archivos del Instituto de Estudios Africanos, nº 80, pp. 21-49.

González de Mendoza y Dorvier, Á. (1972): Prólogo, en M. Alonso Baquer: Aportación militar a la cartografía española en la historia contemporánea. Madrid. Consejo Superior de Investigaciones Científicas, 1972, pp. V-VIII.

Lombardero Vicente, M. (1945): Cartografía del África española, Boletín de la Real Sociedad Geográfica, LXXXI, pp. 403-483.

Martín Corrales, E. (1999): El protectorado español en Marruecos (1912-1956). Una perspectiva histórica, en J. Nogué y J. L. Villanova (eds.): España en Marruecos (1912-1956). Discursos geográficos e intervención territorial. Lleida. Milenio, pp. 143-158.

Montaner Canet, F. (1930): La Comisión Geográfica de Marruecos y Límites en la Feria de Muestras de Melilla. Melilla. Artes Gráficas Postal Exprés.

Morales Lezcano, V. (2006): Historia de Marruecos. Madrid. La Esfera de los Libros, 498 pp.

Muro, J. I., Urteaga, L. y Nadal, F. (2002): La fotogrametría terrestre en España (19141958). Investigaciones Geográficas, Alicante, $n^{\circ} 27,2002$, pp. 151-172. 
Nadal, F., Urteaga, L. y Muro, J. I. (2000): El mapa topográfico del Protectorado de Marruecos en su contexto político e institucional (1923-1940). Documents d'Anàlisi Geogràfica, no 36, 2000, pp. 15-46.

Nogué, J. y Villanova, J. L., eds. (1999): España en Marruecos (1912-1956). Discursos geográficos e intervención territorial. Lleida. Milenio, 570 pp.

Saz, I. (1999): The Second Republic in the international arena, en S. Balfour y P. Preston (eds.): Spain and the Great Powers in the twentieth century. Londres. Routledge, pp. 73-95.

Urteaga, L. (2006a): El mapa del norte de Marruecos a escala 1:500.000 y la Conferencia de Algeciras de 1906, Scripta Nova. Revista electrónica de geografía y ciencias sociales. Barcelona. Universidad de Barcelona, 1 de agosto de 2006, vol. X, $n^{\circ} 218$ (58), http://www.ub.es/geocrit/sn/sn-218-58.htm.

Urteaga, L. (2006b): Vigilia colonial. Cartógrafos militares españoles en Marruecos (1882-1912). Barcelona. Edicions Bellatera y Ministerio de Defensa, 2006, 262 pp.

Urteaga, L. (2007): La cartografía del ejército franquista (1937-1939), en C. Montaner, F. Nadal y L. Urteaga (eds.): Los mapas en la guerra civil española, 1936-1939, Barcelona, Institut Cartogràfic de Catalunya, pp. 47-81.

Urteaga, L., Nadal, F. y Muro, J. I. (2003): Imperialismo y cartografía: la organización de la Comisión española de Estado Mayor en Marruecos (1881-1882), Scripta Nova. Revista electrónica de geografía y ciencias sociales, Barcelona, Universidad de Barcelona, 1 de junio de 2003, vol. VII, n 142, http://www.ub.es/geocrit/sn/sn142.htm.

Urteaga, L., Nadal, F. y Muro, J. I. (2004): Los planos urbanos de la Comisión de Marruecos (1882-1908). Ería. Revista cuatrimestral de Geografía. Oviedo, no 64-65, 2004, pp. 261-283.

Villanova, J. L. (2004): El Protectorado de España en Marruecos. Organización política y territorial. Barcelona. Edicions Bellatera, $380 \mathrm{pp}$.

Villanova, J. L. y Urteaga, L. (2009): Jesús Jiménez Ortoneda, interventor militar en el Rif. Hispania, vol. LXIX, nº 232, pp. 423-448.

\section{RESUMEN}

La Segunda República dedicó cuantiosos recursos, económicos y humanos, a la cartografía de las posesiones coloniales. Los sucesivos gobiernos republicanos mantuvieron una fuerte continuidad, organizativa y funcional, en el ámbito de la cartografía colonial, sin que se detecte ningún cambio significativo respecto a los planes trazados en etapas anteriores. La actividad cartográfica continuó centrada en el territorio de Marruecos, y fue protagonizada por una unidad dependiente del Ministerio de la Guerra, la Comisión Geográfica de Marruecos y Límites. En este trabajo, que se apoya en fuentes primarias, se ofrece una descripción del marco institucional de la cartografía colonial durante el período republicano, se identifica a sus artífices, y se da cuenta de los levantamientos cartográficos realizados. 
Palabras Clave: Cartografía colonial; Protectorado español de Marruecos; Ifni; Comisión Geográfica de Marruecos y Límites; Comisión de Límites de África.

\section{AbSTRACT}

The Spanish Second Republic set aside a big amount of resources, both human and economic, to survey the colonies. The consecutive republican governments kept a strong continuity on the schemes for colonial cartography, with no significant changes over the plans established in past periods. Cartographic work was focused in Morocco's territory, and was carry out by a military unit named Comisión Geográfíca de Marruecos y Límites (Morocco's Geographical Commission). This paper, built on primary sources, examines the institutional framework of Spanish colonial cartography during the republican period, identifies the leading mapmakers, and discusses the main cartographic surveys.

KEY WORDS: Colonial Cartography; Spanish Protectorate of Morocco; Ifni; Morocco's Geographical and Borders Commission; Africa's Borders Commission.

\section{RÉSUMÉ}

La Deuxième République a consacré nombreux ressources, économiques et humains, à la cartographie des possessions coloniales. Les successifs gouvernements républicains ont tenu une forte continuité, d'organisation et fonctionnelle, dans le domaine de la cartographie coloniale, sans qu'on ne puisse détecter aucun changement significatif en relation aux plans tracés en étapes antérieures. Lactivité cartographique a continué centrée sur le territoire du Maroc et a été menée à bien par une unité dépendant du Ministère de la Guerre: la Commission Géographique de Maroc et Limites. Dans ce travail, élaboré à partir de sources primaires, on offre une description du cadre institutionnel de la cartographie coloniale pendant la période républicaine, on identifie à leurs protagonistes et on explique les levées réalisés.

Mots CLÉs: Cartographie coloniales; Protectorat espagnol du Maroc; Ifni; Commission Géographique de Maroc et Limites; Commission de Limites de l'Afrique. 